\title{
Self-assembly of azobenzene based side-chain liquid crystalline polymer and $\boldsymbol{n}$-alkyloxybenzoic acids
}

\author{
KUMARASAMY GAYATHRI, SUBRAMANIAN BALAMURUGAN and \\ PALANINATHAN KANNAN* \\ Department of Chemistry, Anna University, Chennai 600 025, India \\ e-mail: pakannan@annauniv.edu
}

MS received 11 September 2010; revised 4 January 2011; accepted 28 February 2011

\begin{abstract}
Liquid crystalline pendant polymeric complexes have been obtained by supramolecular assembly of two mesogenic components namely, poly[4-(10-acryloyloxydecyloxy)-4' - phenylazobenzonitrile] (P10) and 4-alkyloxybenzoic acids (A7-A12). Hydrogen bond formed between carboxylic acid and cyano moiety served as molecular bridge. The polymeric complexes acquitted as undivided liquid crystalline properties exhibited stable and enantiotropic mesophases. The precursor, monomer and polymer were analysed by ${ }^{1} \mathrm{H}-\mathrm{NMR}$ and ${ }^{13} \mathrm{C}-\mathrm{NMR}$ spectroscopy. The hydrogen bonding interaction in polymer complexes (P10-A7 to P10-A12) was investigated by FT-IR spectroscopy. The thermal behaviours and textural analysis were studied by differential scanning calorimetry and polarized optical microscopy respectively.
\end{abstract}

Keywords. Self-assembly; H-bonding; liquid crystals; nematic phase; smectic-A phase.

\section{Introduction}

Supramolecular liquid crystals obtained via intermolecular $\mathrm{H}$-bonding fascinated attention during the last decade. ${ }^{1-7}$ Molecular interactions received significant influence on the ordering of liquid crystalline state. A powerful tool toward designing of highly organized soft matter arises from strong cohesive forces such as H-bonding between identical or complementary molecules. ${ }^{89}$ A number of such systems have been investigated following the reports of Kato and Frechet Jean ${ }^{10,11}$ and reviewed extensively. ${ }^{12-14}$ Liquid crystalline polymers (LPCs) possess functional materials as electro-optical devices or high-strength fibres. A wide variety of self-organized molecular systems, such as liquid crystals attracted to produce artificial biological systems and other functional materials. ${ }^{15}$ Shandryuk et al. ${ }^{16}$ studied the orientation behaviour of liquid crystal networks having the $\mathrm{SmC}_{A}$ structure stabilized by $\mathrm{H}$-bonds. The hydrogen bonds are responsible for the elastic properties of the liquid crystal polymer network and the mechanism of its plastic flow above the threshold strain. The anisotropy of the mechanical properties of the H-bonded polymer materials is observed in monodomain LC networks. If polymer containing a pendant group capable of forming hydrogen bonding

*For correspondence could be used to stabilize and enhance mesomorphic property and these interactions are much stronger than dipole-dipole interaction. ${ }^{17-19}$ This type of interaction possesses utility in the area of miscibility of liquid crystalline blends and in design of novel guest-host liquid crystalline systems as well. Photoisomerization of azobenzene has been used to design photochromic liquid crystals, as rod-like trans-isomer of azobenzene is known to stabilize LC phase, whereas bent shaped cis-isomer destabilizes this LC phase. ${ }^{20-24}$

Present work deals with the mixing of one independent liquid crystalline component and polymer to form complex with new mesogen (figure 1). The polymer and $n$-alkyloxybenzoic acid were reported in the literature. ${ }^{25-27}$ The magnitude of mesophase stabilization is hitherto unreported in the literature for conventional binary mixtures of this kind of mesogens. Here, Hbonding between fixed polymeric acceptor with varied donors units of 4-alkyloxybenzoic acids were prepared, characterized and discussed.

\section{Experimental}

\subsection{Materials}

Cyanoaniline, sodium hydroxide, phenol, decanediol, acrylic acid, triethylamine and 2, 2'-azobisisobutyronitrile (AIBN) (Merck, Germany), p-hydroxybenzoic 


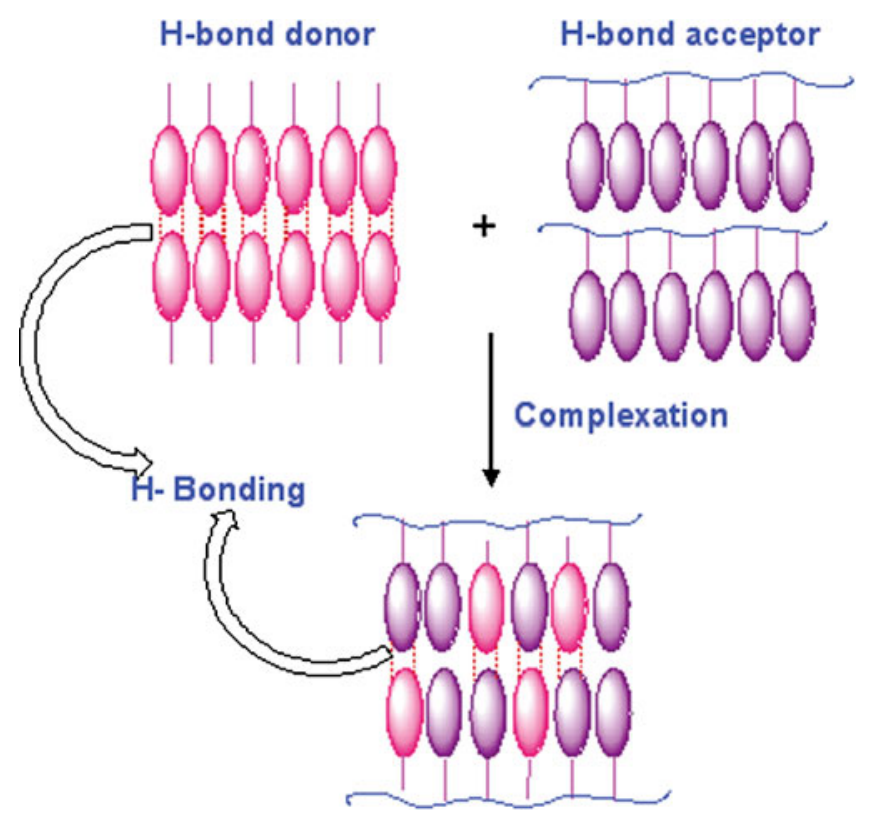

Figure 1. Supramolecular assembly of liquid crystal complexes through $\mathrm{H}$-bonding interactions.

acid and bromoalkanes, these chemicals are AR grade and used as received. Acetone, dichloromethane, THF, diethyl ether, chloroform, dimethylformamide (SRL, India) methanol and other solvents were purified by usual procedures. ${ }^{28}$ Silica gel (100-200 mesh) (SRL, India) was dried in a hot air oven at $100^{\circ} \mathrm{C}$ for $2 \mathrm{~h}$ and cooled before use.

\subsection{Measurements}

Infrared spectra were recorded on a Thermo Electron Corporation Nicolet 380 FT-IR spectrometer. High resolution ${ }^{1} \mathrm{H}$ and ${ }^{13} \mathrm{C}$-NMR spectra were recorded on a Bruker AM-400 spectrometer in $\mathrm{CDCl}_{3}$ with TMS as an internal standard. Elemental analysis was carried out on a Carlo-Erba 1106 system. The weight-average molecular weight $(\overline{\mathrm{Mw}})$, number average molecular weight $(\overline{\mathrm{Mn}})$, polydispersity $(\overline{\mathrm{Mw}} / \overline{\mathrm{Mn}})$ of the polymers were obtained on a PL-GPC model 210 chromatograph using DMF as eluent at $25^{\circ} \mathrm{C}$ and calibrated with polystyrene (molecular weight $1,84,300$ ) standard. The absorption spectra of polymers in spectroscopic grade chloroform solution were recorded on a Shimadzu UV-2450 UVVisible spectrophotometer, barium sulphate was used as a standard. Differential scanning calorimetry (DSC) was conducted on a Perkin-Elmer model DSC Pyris 1 system calibrated with indium and zinc standards with heating rate of $10^{\circ} \mathrm{C} \mathrm{min}^{-1}$. Polarizing microscopic studies were performed with a Euromex polarizing microscope equipped with a Linkem HFS 91 heat- ing stage and a TP -93 temperature programmer. Small quantity of samples were placed between two thin glass cover slips and heating and cooling carried out at the rate of $5^{\circ} \mathrm{C} \mathrm{min}^{-1}$. The photographs were taken using Nikon FM10 camera and exposed on Kodak 200 film.

\subsection{Synthesis of 4-(heptyloxy) benzoic acid (A7)}

Alkylated products of 4-hydroxybenzoic acid were synthesized based on the Williamson aryl ether synthesis conditions. A typical procedure for the synthesis of 4-(heptyloxy) benzoic acid (A7) is as follows: 4hydroxybenzoic acid $(0.01 \mathrm{~mol}, 1.52 \mathrm{~g})$ dissolved in dry DMF $(250 \mathrm{~mL})$, potassium carbonate $(4.95 \mathrm{~g}, 0.05 \mathrm{~mol})$ added and stirred. Then 1-bromoheptane $(3.36 \mathrm{~mL}$, $0.03 \mathrm{~mol}$ ) was added drop-wise to the reaction mixture for $24 \mathrm{~h}$ at $90^{\circ} \mathrm{C}$. At the end of reaction, the mixture was cooled, poured over crushed ice, extracted with diethyl ether and dried over anhydrous sodium sulphate. Then, solvent was evaporated under vacuum and purified by recrystallization using ethanol to get colourless crystalline solid (yield 63\%). A similar procedure was adopted for the synthesis of remaining $O$-alkylated compounds (A8-A12).

Anal. Calcd. for $\mathrm{C}_{13} \mathrm{H}_{18} \mathrm{O}_{3}: \mathrm{C}, 70.24 ; \mathrm{H}, 8.16 ; \mathrm{O}$, 21.59; found: $\mathrm{C}, 70.80 ; \mathrm{H}, 8.24 ; \mathrm{O}, 21.67$. FT-IR $\left(\mathrm{KBr}\right.$ pellet, $\left.\mathrm{cm}^{-1}\right): 2919,2848,1682,1256,945,771$. ${ }^{1} \mathrm{H}$ NMR $\left(\mathrm{CDCl}_{3}, 400 \mathrm{MHz}\right), \delta(\mathrm{ppm}): 11.02(\mathrm{~s}, 1 \mathrm{H}$, -COOH), 8.12 (d, 2H, Ar-H), 6.96 (d, 2H, Ar-H), 4.01 $\left(\mathrm{t}, 2 \mathrm{H},-\mathrm{OCH}_{2}\right), 1.81$ (q, 2H, $\left.-\mathrm{CH}_{2}\right), 1.24-1.39(\mathrm{~m}, 6 \mathrm{H}$, $\left.-\mathrm{CH}_{2}\right), 0.93\left(\mathrm{t}, 3 \mathrm{H},-\mathrm{CH}_{3}\right) \cdot{ }^{13} \mathrm{CNMR}\left(75 \mathrm{MHz}, \mathrm{CDCl}_{3}\right)$ : $\delta=172.2,163.7,132.3,121.4,114.18,68.2,31.6,29.0$, 25.8, 22.5 .

\subsection{Synthesis of 4-(4-hydroxyphenylazo)benzonitrile}

4-(4'-Hydroxyphenylazo)benzonitrile was prepared using a common procedure as follows: 4-cyanoaniline $(6.8 \mathrm{~g}, \quad 0.07 \mathrm{~mol})$ was dissolved in concentrated hydrochloric acid $(16 \mathrm{~mL})$ and water $(16 \mathrm{~mL})$ contained in a conical flask. The dissolved 4-cyanoaniline was diazotized by slow addition of sodium nitrite solution $\left(0.07 \mathrm{~mol}, 4.83 \mathrm{~g}\right.$ in $20 \mathrm{~mL}$ of water) at below $5^{\circ} \mathrm{C}$. Phenol $(6.15 \mathrm{~g}, 0.07 \mathrm{~mol})$ was dissolved in sodium hydroxide solution $(10 \% ; 45 \mathrm{~mL})$ in a $250 \mathrm{~mL}$ beaker and cooled the solution to $5^{\circ} \mathrm{C}$. The phenolic solution was vigorously stirred and cold diazonium salt solution added drop-wise, then, the mixture was kept in an ice bath for $30 \mathrm{~min}$ with occasional stirring. The mixture was filtered through a Buchner funnel with gentle suction, washed well with water. The precipitate was dried 
in vacuum oven at $60^{\circ} \mathrm{C}$ for 2 days. Resultant product was recrystallized from chloroform to get orange-red coloured solid, (yield: $10.8 \mathrm{~g}, 68 \%$ ).

Anal. Calcd. for $\mathrm{C}_{13} \mathrm{H}_{9} \mathrm{~N}_{3} \mathrm{O}: \mathrm{C}, 69.95 ; \mathrm{H}, 4.06 ; \mathrm{N}$, 18.82; O, 7.17; found: C, 69.90; H, 4.00; N, 18.75; O, 7.21. FT-IR ( $\mathrm{KBr}$ pellet, $\mathrm{cm}^{-1}$ ): 3619, 2235, 1582, 1475. ${ }^{1} \mathrm{H}$ NMR $\left(\mathrm{CDCl}_{3}, 400 \mathrm{MHz}\right), \delta(\mathrm{ppm}): 7.92(\mathrm{~d}$, 2H, Ar-H), 7.80 (d, 4H, Ar-H), 7.26(s, 1H, Ar-H), 6.98 $(\mathrm{d}, 2 \mathrm{H}, \mathrm{Ar}-\mathrm{H}){ }^{13} \mathrm{CNMR}\left(75 \mathrm{MHz}, \mathrm{CDCl}_{3}\right): \delta=159.5$, 154.7, 146.9, 133.1, 125.6, 123.1, 118.1, 116.0, 113.2.

\subsection{Synthesis of 4-(10-hydroxydecyloxy)-4' - phenylazobenzonitrile}

4-(10-Hydroxydecyloxy)-4'-phenylazobenzonitrile was synthesized by adopting a similar procedure reported elsewhere. ${ }^{26}$ A suspension of anhydrous $\mathrm{K}_{2} \mathrm{CO}_{3}(11 \mathrm{~g}$ $0.08 \mathrm{~mol})$, pinch of $\mathrm{KI}$ and 4-(4'-hydroxyphenylazo)benzonitrile $(4.5 \mathrm{~g}, 0.02 \mathrm{~mol})$ in dry DMF $(80 \mathrm{~mL})$ was refluxed with stirring for $1 \mathrm{~h}$. 10-Bromodecanol $(0.024 \mathrm{~mol}, 4.78 \mathrm{~mL})$ was added drop-wise to the reaction mixture and refluxed additionally for $48 \mathrm{~h}$. After completion of reaction, the mixture was filtered and washed with excess of DMF. The filtrate was poured in ice water, extracted using diethyl ether and dried with anhydrous sodium sulphate. Solvent was removed under vacuum and purified by column chromatography (silica gel, chloroform) to afford $5.63 \mathrm{~g}$ of compound as orange coloured solid (yield $75 \%$ ).

Anal. Calcd. for $\mathrm{C}_{21} \mathrm{H}_{25} \mathrm{~N}_{3} \mathrm{O}_{2}: \mathrm{C}, 71.77 ; \mathrm{H}, 7.17 ; \mathrm{N}$, 11.96; O, 9.10,; found: C, 71.70; H, 7.20; N, 11.96; O, 9.14. FT-IR ( $\mathrm{KBr}$ pellet, $\left.\mathrm{cm}^{-1}\right): 3591,2916,2850$, $2235,1600,1583,1475 .{ }^{1} \mathrm{H} \mathrm{NMR}\left(\mathrm{CDCl}_{3}, 400 \mathrm{MHz}\right), \delta$ (ppm): 7.85 (d, 4H, Ar-H), 7.71(d, 2H, Ar-H), 7.19(s, $1 \mathrm{H},-\mathrm{OH}), 6.94(\mathrm{~d}, 2 \mathrm{H}, \mathrm{Ar}-\mathbf{H}), 3.98\left(\mathrm{t}, 2 \mathrm{H},-\mathrm{OCH}_{2}\right)$, 3.56 (t, 2H, $\left.-\mathrm{OCH}_{2}\right), 1.75$ (q, 2H, $\left.-\mathrm{CH}_{2}\right), 1.25-1.51$ $\left(\mathrm{m}, 12 \mathrm{H},-\mathrm{CH}_{2}\right) \cdot{ }^{13} \mathrm{CNMR}\left(75 \mathrm{MHz}, \mathrm{CDCl}_{3}\right): \delta=$ 162.7, 154.8, 146.7, 133.1, 125.4, 123.0, 118.6, 114.8, $113.1,68.4,63.0,32.7,29.5,29.4,29.3,29.1,25.9$, 25.7.

\subsection{Synthesis of 4-(10-acryloyloxydecyloxy)-4' - phenylazobenzonitrile}

4-(10-Hydroxydecyloxy)-4'-phenylazobenzonitrile $(2.39 \mathrm{~g}, \quad 4.4 \mathrm{mmol})$ and triethylamine $(1.16 \mathrm{~mL}$, $8.0 \mathrm{mmol}$ ) were dissolved in dry THF under nitrogen atmosphere and stirred around $5-10^{\circ} \mathrm{C}$. Acryloyl chloride $(0.78 \mathrm{~mL}, 8.0 \mathrm{mmol})$ in dry THF solution was added drop-wise over a period of $30 \mathrm{~min}$, then the mixture was warmed to room temperature and stirred for $12 \mathrm{~h}$. Precipitated amine hydrochloride was filtered and solvent evaporated under vacuum. Crude product was dissolved in ethyl acetate, washed with water $(3 \times 100 \mathrm{~mL})$, brine solution $(3 \times 100 \mathrm{~mL})$ and dried over anhydrous sodium sulphate. Solvent was removed under vacuum then residue purified by column chromatography in silica-gel, hexane and ethyl acetate (9: $1 \mathrm{v} / \mathrm{v}$ ) used as a eluent to give $2.21 \mathrm{~g}$ of monomer as yellow-orange coloured solid (yield 92\%).

Anal. Calcd. for $\mathrm{C}_{24} \mathrm{H}_{27} \mathrm{~N}_{3} \mathrm{O}_{3}$ : C, 71.09; $\mathrm{H}, 6.71$; $\mathrm{N}, 10.36$; O, 11.84; found: C, 71.01; H, 6.74; N, 10.40; O, 11.84. FT-IR (KBr pellet, $\mathrm{cm}^{-1}$ ): 2916, 2850, $2235,1600,1747,1583,1475,1154 .{ }^{1} \mathrm{H}$ NMR $\left(\mathrm{CDCl}_{3}\right.$, $400 \mathrm{MHz}), \delta(\mathrm{ppm}): 7.87(\mathrm{~d}, 4 \mathrm{H}, \operatorname{Ar}-\mathbf{H}), 7.71(\mathrm{~d}$, $2 \mathrm{H}, \mathrm{Ar}-\mathbf{H}), 6.94(\mathrm{~d}, 2 \mathrm{H},-\mathrm{Ar}-\mathrm{CH}), 6.05(\mathrm{~d}, 1 \mathrm{H}$, acryloyl-CH $\left.\mathrm{CH}_{2}\right), 5.72(\mathrm{~d}, 1 \mathrm{H}$, acryloyl-CH$), 4.07(\mathrm{t}, 2 \mathrm{H}$, $\left.-\mathrm{OCH}_{2}\right), 3.97$ (t, 2H, $\left.-\mathrm{OCH}_{2}\right), 2.09$ (s, 1H, acryloylCH), 1.77 (q, 2H, $-\mathrm{CH}_{2}$ ), $1.72\left(\mathrm{q}, 2 \mathrm{H},-\mathrm{CH}_{2}\right), 1.17-$ $1.42\left(\mathrm{~m}, 10 \mathrm{H},-\mathrm{CH}_{2}\right) \cdot{ }^{13} \mathrm{CNMR}\left(75 \mathrm{MHz}, \mathrm{CDCl}_{3}\right): \delta=$ $164.9,161.3,153.4,145.2,131.8,131.7,129.0,127.2$, 124.0, 123.2, 121.9, 121.6, 117.2, 113.4, 111.7, 67.0, $63.2,28.0,27.9,27.8,27.7,27.2,24.5,24.4$.

\subsection{Synthesis of poly[4-(10-acryloyloxydecyloxy)-4' - phenylazobenzonitrile] (P10)}

4-(10-Acryloyloxydecyloxy)-4'-phenylazobenzonitrile (400 mg, $0.67 \mathrm{mmol})$ and AIBN (2 wt \%) were dissolved in dry THF and gentle steam of nitrogen purged into solution in polymerization tube. The tube was kept in an oil bath at $60^{\circ} \mathrm{C}$ for $48 \mathrm{~h}$. Then the solution was cooled and poured into excess of dry methanol to precipitate the product. Crude polymer thus obtained was reprecipitated twice using chloroform and dried at $45^{\circ} \mathrm{C}$ under vacuum for $48 \mathrm{~h}$ to afford orange coloured powder (yield: $256 \mathrm{mg}, 56 \%$ ).

M. P. $52-94^{\circ}$ C. FT-IR $\left(\mathrm{KBr}\right.$ pellet, $\left.\mathrm{cm}^{-1}\right): 2916$, 2851, 2235, 1600, 1747, 1582, 1475, 1153. ${ }^{1} \mathrm{H}$ NMR $\left(\mathrm{CDCl}_{3}, 400 \mathrm{MHz}\right), \delta(\mathrm{ppm}): 7.82(\mathrm{~m}, 4 \mathrm{H}, \mathrm{Ar}-\mathbf{H})$, 6.94(m, 4H, Ar-H), $3.83\left(\mathrm{~m}, 4 \mathrm{H},-\mathrm{OCH}_{2}\right), 0.87-1.75$ $\left(\mathrm{m}, 16 \mathrm{H},-\mathrm{CH}_{2}\right) \cdot{ }^{13} \mathrm{CNMR}\left(75 \mathrm{MHz}, \mathrm{CDCl}_{3}\right): \delta=$ $161.4,161.1,147.0,146.8,124.3,114.6,114.1,55.5$, 29.5, 29.2, 28.1, 26.0 .

\subsection{Preparation of hydrogen bonded polymer complexes}

All polymer complexes investigated in the present study were prepared by evaporation technique from THF solution containing equimolar amounts of donor 
(46 mmol) and acceptor $(46 \mathrm{mmol})$ moieties. The solvent was evaporated slowly at room temperature followed by drying in vacuum at $40^{\circ} \mathrm{C}$.

\section{Results and discussion}

\subsection{Synthesis and characterization}

The synthetic route for the preparation of various alkyloxybenzoic acids, polymer and its hydrogen bonded complexes are shown in scheme 1. The monomer was polymerized by free radical addition polymerization method in the presence of AIBN at $60^{\circ} \mathrm{C}$ in THF. Polymer is soluble in DMF, $\mathrm{CHCl}_{3}, \mathrm{CH}_{2} \mathrm{Cl}_{2}$ and acetone where as insoluble in methanol, ethanol, 2propanol, benzene and toluene. Table 1 shows thermal properties, molecular weights and UV-vis absorp- tion maximum of polymer. Structures of precursors and 4-alkyloxybenzoic acids (donors) were confirmed by FT-IR, ${ }^{1} \mathrm{H}$ and ${ }^{13} \mathrm{C}$-NMR spectroscopy and elemental analysis. Spectral values are in accordance with assigned structures (see Supporting information, figure S1). The carboxylic acid proton resonated at $11.02 \mathrm{ppm}$ of 4-alkyloxybenzoic acids. The resonance around 6.96-8.12 ppm and $0.93-4.01 \mathrm{ppm}$ are ascribed to aromatic and aliphatic regions respectively. In polymer, aromatic proton resonated around 6.94-7.82 ppm, alkyl proton linked with ether resonated at $3.83 \mathrm{ppm}$ and disappearance of acrylic protons at $6.05,5.72$, $2.09 \mathrm{ppm}$ confirmed polymerization reaction (see Supporting information, figure S2). The ester group resonated at $161.4 \mathrm{ppm}, \mathrm{C} \equiv \mathrm{N}$ signal of nitrile group at $114.6 \mathrm{ppm}$, together with carbon signal for aromatic ring around 114.1-161.1 ppm. The carbon in aliphatic chains resonated around $26.0-55.5 \mathrm{ppm}$. Structures of

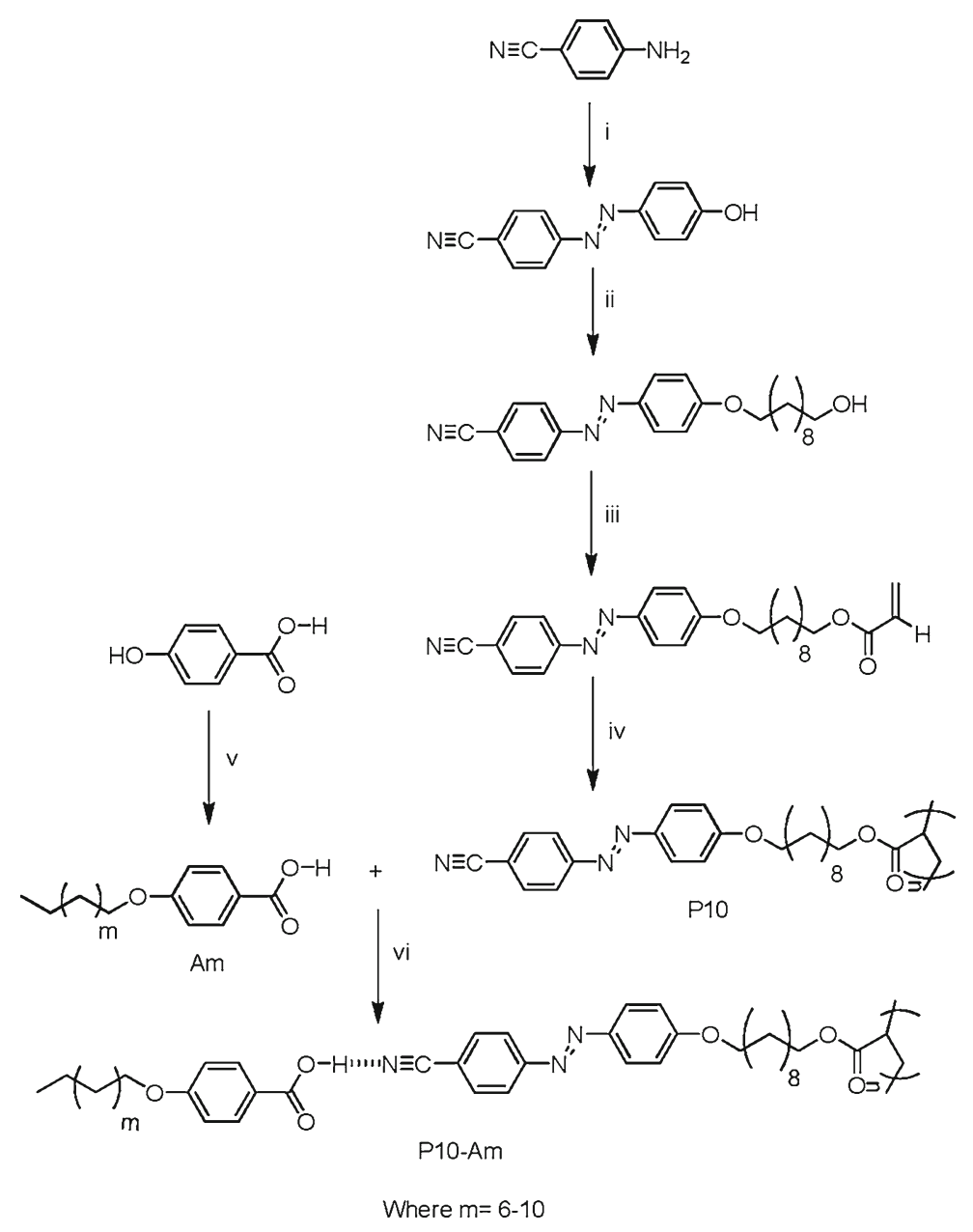

Reagents: i) $\mathrm{HCl} / \mathrm{NaNO}_{2}$ \& phenol/ $\mathrm{NaOH}$ ii) $\mathrm{K}_{2} \mathrm{CO}_{3} / \mathrm{Kl}$, DMF iii) Acryloyl chloride, TEA, THF iv) AIBN, THF v) $\mathrm{K}_{2} \mathrm{CO}_{3} / \mathrm{KI}$, DMF vi) THF

Scheme 1. Synthesis of hydrogen bonded polymer complexes. 
Table 1. DSC, GPC and UV data of polymer.

\begin{tabular}{|c|c|c|c|c|c|c|c|}
\hline & \multicolumn{4}{|c|}{ Thermal properties $\left({ }^{\circ} \mathrm{C}\right) \mathrm{TGA}$} & \multicolumn{2}{|c|}{ GPC } & \multirow{2}{*}{$\frac{\mathrm{UV}}{\lambda \max (\mathrm{nm}) \mathrm{CHCl}_{3}}$} \\
\hline & $\mathrm{T}_{\mathrm{g}}$ & $\mathrm{T}_{\mathrm{m}}$ & $\mathrm{T}_{\mathrm{i}}$ & $\mathrm{T}_{\mathrm{d}}$ & $(\overline{\mathrm{Mn}})$ & $(\overline{\mathrm{Mw}} / \overline{\mathrm{Mn}})$ & \\
\hline Polymer & - & 52 & 94 & $336^{\mathrm{a}}, 418^{\mathrm{b}}$ & $1,33,000$ & 1.28 & 360 \\
\hline
\end{tabular}

$\mathrm{T}_{\mathrm{g}}$, glass transition; $\mathrm{T}_{\mathrm{m}}$, melting; $\mathrm{T}_{\mathrm{i}}$, isotropic; $\mathrm{T}_{\mathrm{d}}$, decomposition; ${ }^{\mathrm{a} F i r s t}$ decomposition; ${ }^{\mathrm{b}}$ Second decomposition; $(\overline{\mathrm{Mw}})$, Weight average molecular weight; $(\overline{\mathrm{Mn}})$, number average molecular $(\overline{\mathrm{Mw}} / \overline{\mathrm{Mn}})$, molecular weight distribution

multifunctional H-bonding molecules used in the present study are shown in scheme 1 . Here, P10 containing pendant nitrile group acts as an H-bond acceptor and 4-alkyloxybenzoic acids (A7-A12) act as Hbonding donors, both donor and acceptor components show liquid crystalline property at different temperatures. H-bonded complexes were prepared by maintaining 1:1 stoichiometry of nitrile and carboxylic acids.

Infrared spectra of 4-decyloxybenzoic acid (A10), polymer (P10) and polymer complex (P10-A10) are depicted in figure 2. The spectra of free 4-decyloxybenzoic acid shows sharp band at $1678 \mathrm{~cm}^{-1}$ ascribed $\mathrm{C}=\mathrm{O}$ stretching, a strong intense band at $3449 \mathrm{~cm}^{-1}$ assigned to $\mathrm{OH}$ - stretching of the carboxylic acid group and fermi resonances are observed at 2664 and $2556 \mathrm{~cm}^{-1}$ in A10. ${ }^{29}$ The IR spectrum of polymer (P10) exhibits an intense band at $2221 \mathrm{~cm}^{-1}$ attributed to $\mathrm{C}=\mathrm{N}$ stretching. The infrared absorbance of complexes display a sharp band at $1722 \mathrm{~cm}^{-1}$ ascribed to $\mathrm{C}=\mathrm{O}$ stretching of benzoic acid moiety. When compared to 4-decyloxybenzoic acid spectrum, the polymer complexes indicate higher frequency shifts $\left(\sim 44 \mathrm{~cm}^{-1}\right)$ in the $\mathrm{C}=\mathrm{O}$ stretching of benzoic acid moiety and cyano $\left(\sim 11 \mathrm{~cm}^{-1}\right)$ group of polymer. These shifts strongly suggest the formation of intermolecular H-bonding between carboxylic acid and cyano groups. The H-bonded network structures have been obtained by predominant formation of thermodynamically favoured intermolecular $\mathrm{H}$-bonds between individual components. ${ }^{30}$ It is interesting to note that the stable liquid crystalline behaviour maintained for $\mathrm{H}$-bonded networks built from multifunctional compounds.

\subsection{Mesomorphic property of polymer (P10)}

The liquid crystalline property of polymer was evaluated with polarized optical microscopy (POM) and differential scanning calorimetry (DSC) measurements. Optical texture of polymer exhibited nematic and SmA mesophases ${ }^{28}$ while cooling from isotropic liquid.

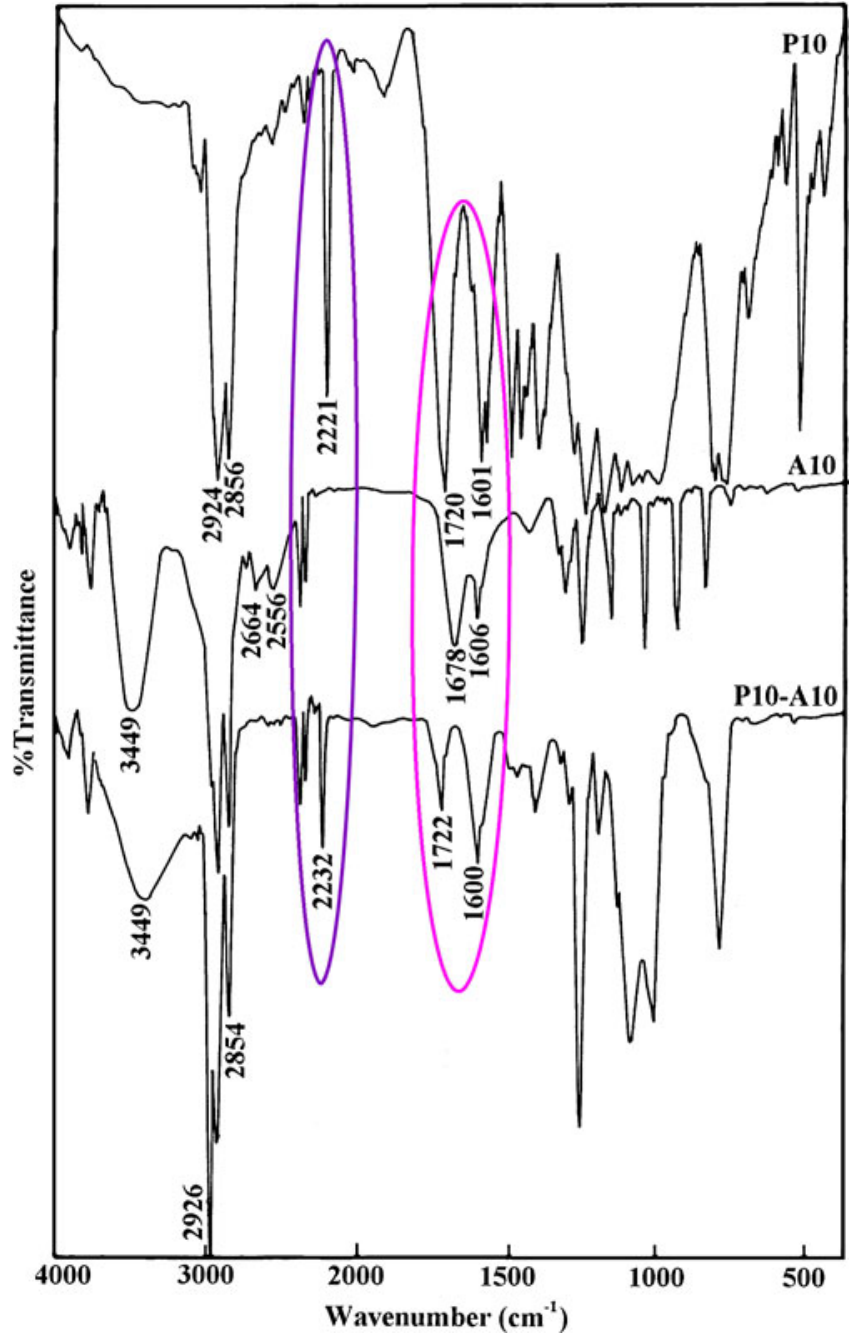

Figure 2. FT-IR spectra of A10, P10 and P10-A10.

Transition temperature of these mesophase is $\mathrm{Cr}-\mathrm{SmA}$ at $52^{\circ} \mathrm{C}, \mathrm{SmA}-\mathrm{N}$ at $58^{\circ} \mathrm{C}$ and $\mathrm{N}-\mathrm{I}$ at $94^{\circ} \mathrm{C}$ (figure 3). Formation of nematic mesophase was identified by schlieren texture with observation of flashlight while applying small mechanical stress on the liquid crystalline melt. ${ }^{29}$ DSC thermogram confirms the formation of liquid crystalline phases for polymer. Azobenzene containing polymer was established two endothermic 

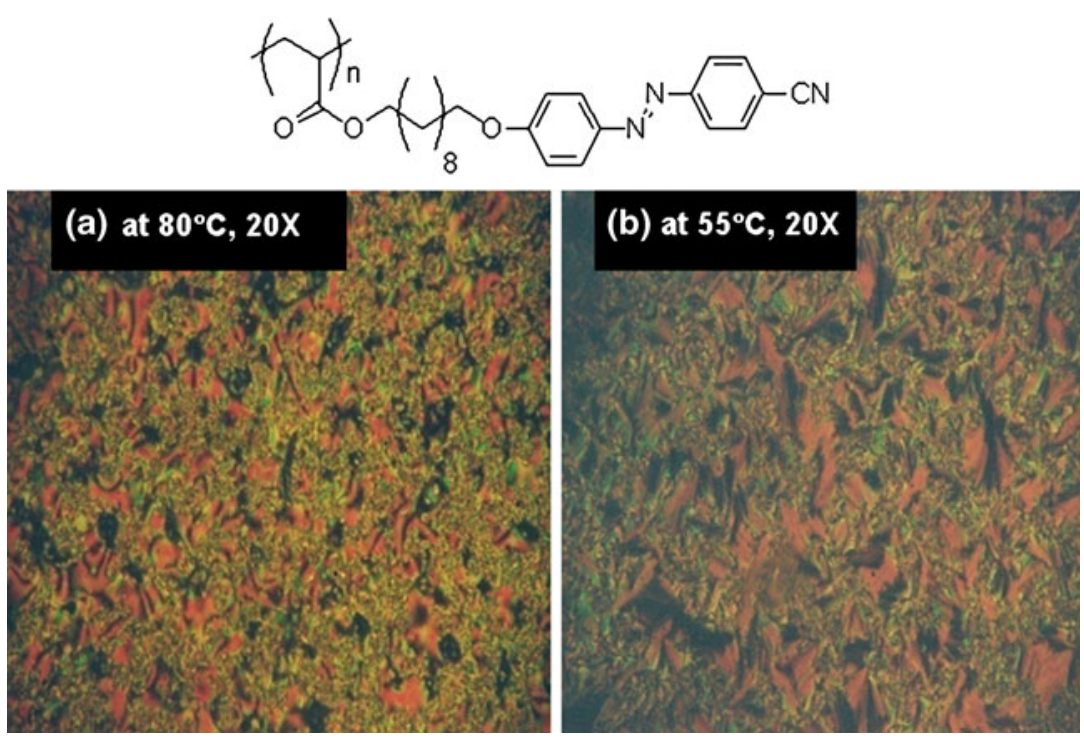

Figure 3. POM photographs of polymer (a) nematic at $80^{\circ} \mathrm{C}$, (b) Sm-A at $55^{\circ} \mathrm{C}$ on cooling from isotropic.

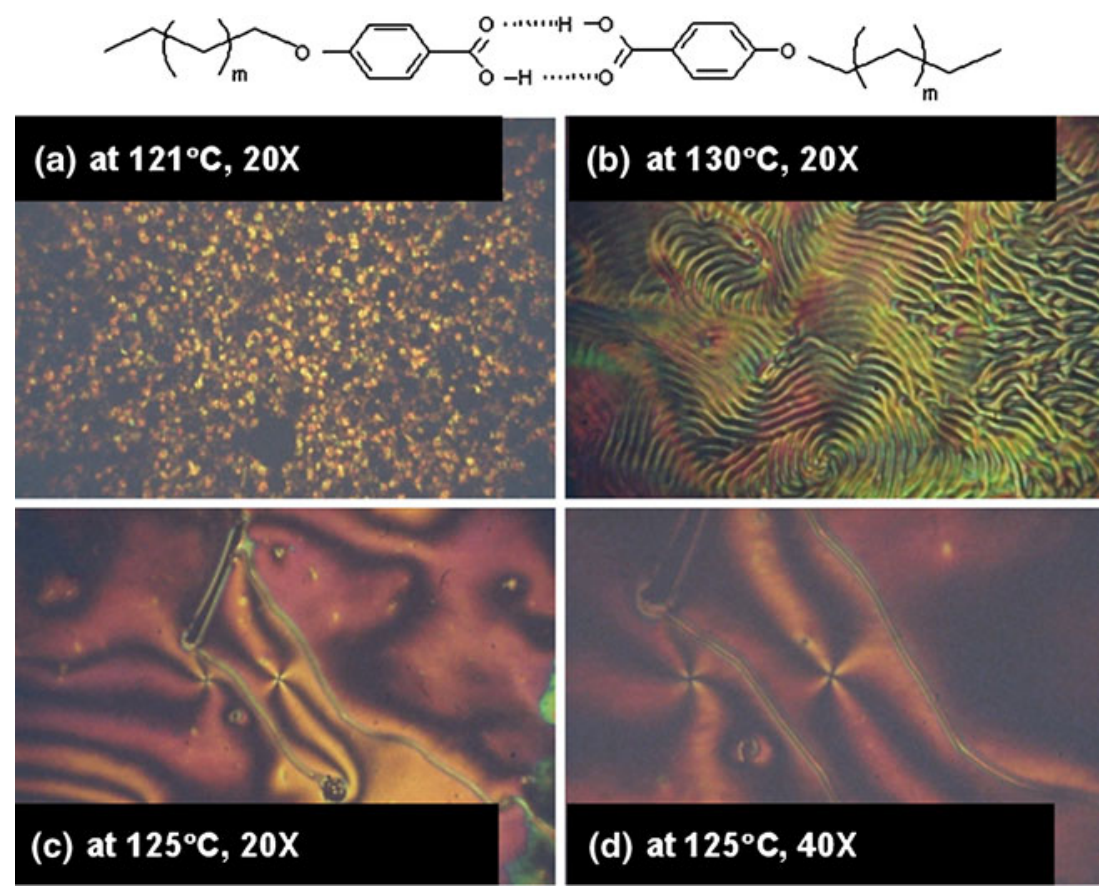

Figure 4. POM photographs of (a) A8 - nematic droplet; (b) A10 - nematic; (c) A12 - schlieren nematic; and (d) A12 - schlieren nematic.

transitions in between 52 and $94^{\circ} \mathrm{C}$. Two endothermic transitions noticed correspond to crystalline-liquid crystalline $(\mathrm{Tm})$ and liquid crystalline-isotropic (Ti) transition temperatures respectively. In addition to endothermic transitions, azobenzene containing polymer exhibited one small hump just below Tm corresponding to glass transition temperature. The $\Delta \mathrm{T}$ $(\Delta \mathrm{T}=\mathrm{Ti}-\mathrm{Tm})$ data indicated that polymer possesses stable mesophases.

\subsection{Mesomorphic property of 4-(alkyloxy)benzoic} acids (A7-A12)

Carboxylic acids were the first compounds discovered to exhibit liquid crystal behaviour due to H-bonding. The mesogenicity of those compounds attributed to H-bonded dimerization leading to lengthening of rigid core moiety that promotes liquid crystallinity. The homologous series of 4-(alkyloxy)benzoic acids 
Table 2. Phase transition temperature of A7-A12.

\begin{tabular}{|c|c|c|c|c|c|c|c|}
\hline \multirow[t]{2}{*}{ Compound } & \multicolumn{7}{|c|}{ Phase transition temperature $\left({ }^{\circ} \mathrm{C}\right)$} \\
\hline & $\mathrm{Cr}$ & & $\mathrm{SmA}$ & & $\mathrm{N}$ & & $\overline{\mathrm{I}}$ \\
\hline A7 & $*$ & 92 & $*$ & 98 & * & 146 & $*$ \\
\hline A8 & $*$ & 101 & $*$ & 108 & $*$ & 147 & $*$ \\
\hline A9 & $*$ & 97 & & & $*$ & 150 & $*$ \\
\hline A10 & $*$ & 94 & $*$ & 117 & $*$ & 147 & $*$ \\
\hline A11 & $*$ & 94 & $*$ & 121 & $*$ & 138 & $*$ \\
\hline A12 & $*$ & 77 & & & $*$ & 136 & $*$ \\
\hline
\end{tabular}

(A7-A12) were exhibited liquid crystalline phases (figure 4). LC property of all compounds was evaluated with DSC measurements. Phase transition data of 4-alkyloxybenzoic acids are listed in table 2. In this series of compounds A7, A8, A10, and A11 exhibited smectic and nematic phases; on the other hand, $\mathbf{A 9}$ and A12 rendered nematic mesophases.

\subsection{Mesomorphic property of H-bonded complexes of P10-A7 to P10-A12}

All the complexes examined in the present study were prepared by evaporation technique from THF solution containing equimolar amounts of polymer and 4-alkyloxybenzoic acids followed by drying in room temperature slowly. Phase transition temperature is differing from that of an individual component indicates the formation of $\mathrm{H}$-bonding between acid and cyano group in the polymer complex. The complexes from P10-A7 to P10-A12 behaved as undivided polymeric components and exhibited liquid crystallinity. All the complexes displayed nematic phase and some of them exhibited SmA as well. The POM image of complexes is depicted in figure 5. Traces of DSC thermogram of complexes P10-A7 to P10-A12 is observed in second heating cycle (see supporting information figure S3). Phase transition temperatures and enthalpy changes were measured from DSC are tabulated in table 3.

Tm was observed in the range of $61.9-110.3^{\circ} \mathrm{C}$ in these series of compounds. Polymer complex P10A7 establishes SmA phase between the temperatures of 103.2 and $112.0^{\circ} \mathrm{C}$ and further heating it displayed nematic phase around $112-134.3^{\circ} \mathrm{C}$. This mesophase transition trends was exhibited by P10-A11 and P10A12, whereas P10-A10 exhibited solely nematic phase. The P10-A7 to P10-A12 renders mesophase duration $(\Delta \mathrm{T})$ at different ranges of temperatures (table 3$)$. Here, P10-A11 possesses maximum duration $72.0^{\circ} \mathrm{C}$. P10A7 and P10-A8 possess minimum mesophase duration $28.1^{\circ} \mathrm{C}$ and $30.1^{\circ} \mathrm{C}$ respectively. This mesophase dura-
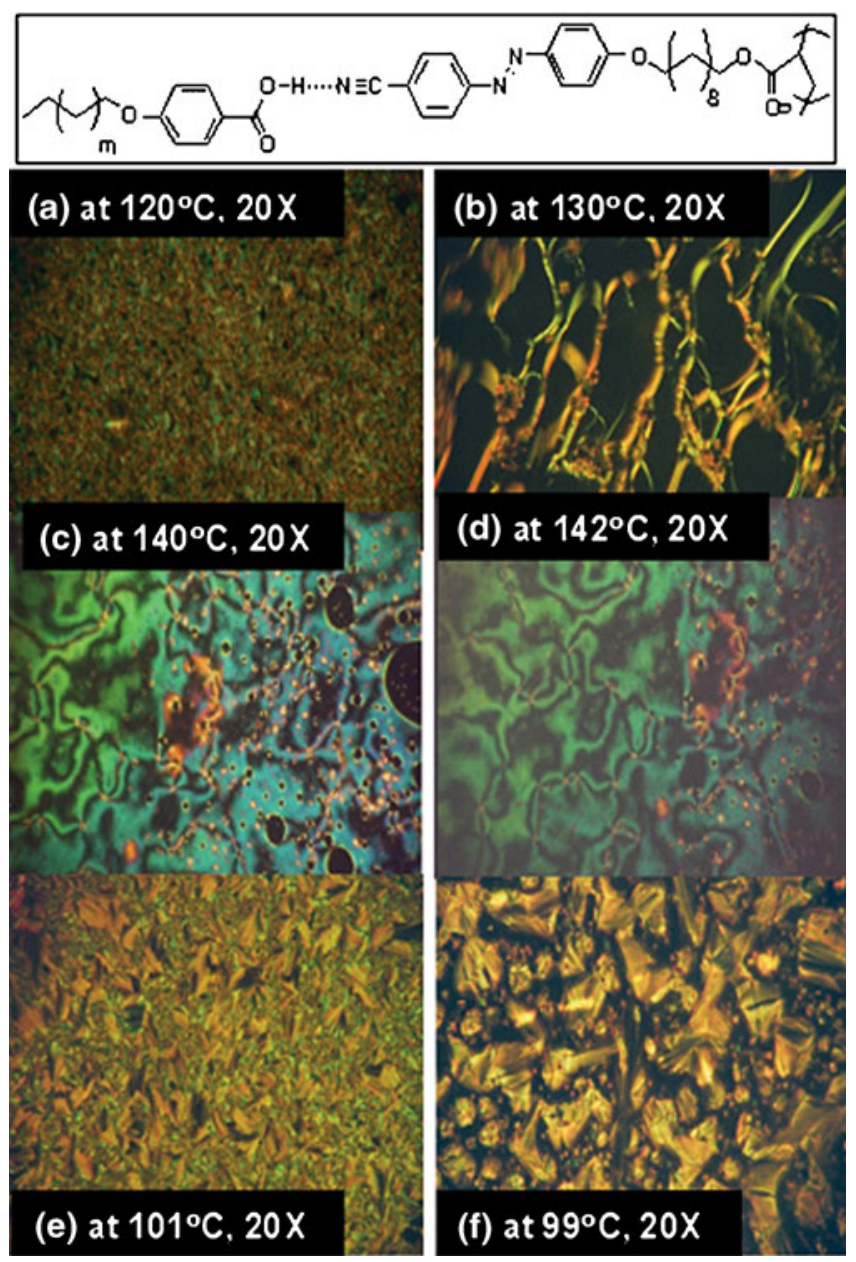

Figure 5. POM photographs of (a) P10-A7-nematic droplet; (b) P10-A8-nematic; (c) P10-A9-schlieren nematic; (d) P10-A10 - schlieren nematic; (e) P10-A11-smectic-A; and (f) P10-A12-smectic-A.

tion was increased with increasing the terminal spacer length of 4-alkyloxybenzoic acids. The $\Delta \mathrm{T}$ values of these series are calculated in POM study was in accordance with DSC measurements. The melting temperature $(\mathrm{Tm})$ and isotropic temperature (Ti) also increased with respect to increasing terminal chain length of 4alkyloxybenzoic acids. This trend was maintained up 
Table 3. Phase transition temperature and associated transition enthalpy values $(\Delta \mathrm{H}, \mathrm{J} / \mathrm{g})$ in parentheses for polymer complexes.

\begin{tabular}{|c|c|c|c|c|c|c|c|c|}
\hline \multirow[t]{2}{*}{ Complexes } & \multicolumn{8}{|c|}{ DSC DATA $\left({ }^{\circ} \mathrm{C}\right)$} \\
\hline & $\mathrm{Cr}$ & & $\mathrm{SmA}$ & & $\mathrm{N}$ & & I & $\Delta \mathrm{T}(\square \mathrm{C})$ \\
\hline P10-A 7 & $*$ & $103.2(12.8)$ & $*$ & $112.0(9.9)$ & $*$ & 134.3 (11.9) & $*$ & 28.1 \\
\hline P10-A8 & $*$ & 107.6 (15.9) & & & $*$ & 137.7 (19.2) & $*$ & 30.1 \\
\hline P10-A9 & $*$ & $110.3(22.1)$ & & & $*$ & $143.0(26.4)$ & $*$ & 36.8 \\
\hline P10-A10 & $*$ & $96.8(14.0)$ & & & $*$ & $148.5(8.5)$ & $*$ & 49.4 \\
\hline P10-A11 & $*$ & $63.5(20.7)$ & $*$ & $108.3(5.2)$ & $*$ & $136.1(24.3)$ & $*$ & 72.0 \\
\hline P10-A12 & $*$ & $61.9(14.3)$ & $*$ & $101.1(13.6)$ & $*$ & $127.6(11.7)$ & $*$ & 66.8 \\
\hline
\end{tabular}

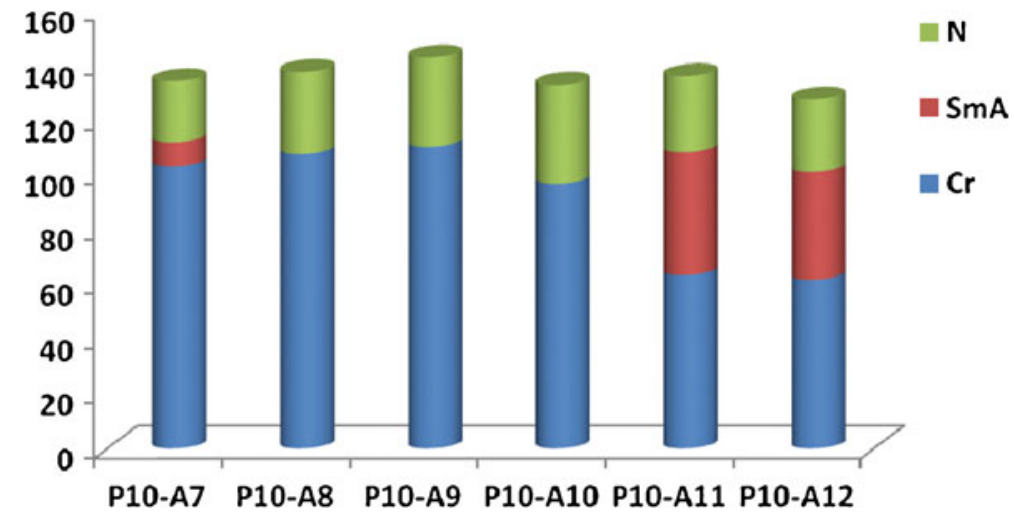

Figure 6. Graphical representations of the phase transition temperatures of P10-A7 to P10-A12.

to the carbon chain length nine after that this transition steeply decreased with increasing chain lengths. The transitions observed under POM were found to be agreed with DSC results. The correlation between the series of complexes and transition temperatures (Tm and Ti) noticed from DSC measurement is shown in figure 6. The isotropic temperature of P10-A7 to P10 A12 were decreased with respect to individual compounds A7-A12 respectively, moreover, the mesomorphic range also drastically increased. The hydrogen bonded complex also exhibit absorption maximum at $366 \mathrm{~nm}$ and the absorption obtained as broader due to tight packing of molecule in the solid state. The azobenzene containing polymer in chloroform solution shows strong absorption band in the range of $366 \mathrm{~nm}$ corresponds to the strong symmetry allowed $\pi-\pi^{*}$ electronic transition and the small absorption band in the range of $440-473 \mathrm{~nm}$ corresponds to the weak symmetry forbidden $n-\pi^{*}$ transition of the trans-configuration of azobenzene units (see supporting information figure S4).

\section{Conclusions}

The precursors, monomer, polymer and polymer complexes were characterized by FT-IR, ${ }^{1} \mathrm{H}-\mathrm{NMR}$ and
${ }^{13} \mathrm{C}-\mathrm{NMR}$ spectroscopy and in good agreement with that of corresponding structures. The liquid crystalline behaviour of polymer, 4-alkyloxybenzoic acids, dimers and hydrogen bonded polymer complexes were confirmed by POM and DSC analysis. The polymer exhibited smectic-A and nematic textures. 4Alkyloxybenzoic acids (A7-A12) displayed nematic and smectic phases at various temperatures. The polymer complexes evidenced nematic mesophase, but P10-A7, P10-A11 and P10-A12 exhibited nematic as well as Sm-A mesophases. The P10-A11 and P10-A7 render maximum and minimum mesophase durations of $72.6^{\circ} \mathrm{C}$ and $28.1^{\circ} \mathrm{C}$ respectively. This mesophase duration was increased with increasing terminal spacer length of 4-alkyloxybenzoic acids. This type of interaction has usefulness in the area of miscibility of liquid crystalline blends in the design of novel guest-host liquid crystalline systems.

\section{Supplementary materials}

Figures S1-S4 are given as supplementary information (see the website: www.ias.ac.in/chemsci).

\section{Acknowledgements}

The authors sincerely acknowledge the University Grants Commission (UGC), New Delhi, Government 
of India [F. 31-110/2005 (SR)] and S B gratefully acknowledges the Council of Scientific and Industrial Research (CSIR), New Delhi, India, for the award of Senior Research Fellowship.

\section{References}

1. Kumar U and Frechet Jean M J 1992 Adv. Mater. 4 665

2. Saravanan C, Deepa M, Kannan P and Senthil S 2008 Z. Naturforsch. 63b 571

3. Bladdon P and Griffin A C 1993 Macromolecules 26 6604

4. Saravanan C, Ambili V and Kannan P 2010 React. Func. Polym. 70217

5. Toh C L, Xu J, Lu X and He C 2008 Liq. Cryst. 35241

6. Thote A J and Gupta R B 2003 Ind. Eng. Chem. Res. 42 1129

7. Li J, Wisner J A and Jennings M C 2007 Org. Lett. 9 3267

8. Paraschiv I, Delforterie P, Giesbers M, Posthumus M A, Marcelis A T M, Zuilhof H and Sudholter E J R 2005 Liq. Cryst. 32977

9. Kohlmeier A, Nordsieck A and Janietz D 2009 Chem. Mater. 21491

10. Kato T and Frechet Jean M J 1989 Macromolecules 2 3818

11. Kato T and Frechet Jean M J 1989 J. Am. Chem. Soc. 1118533

12. Tschierske C 2001 J. Mater. Chem. 112647
13. Kato T, Mizoshita $\mathrm{N}$ and Kishimoto K 2006 Angew. Int. Ed. 4538

14. Paleos C M and Tsiourvas D 2001 Liq. Cryst. 281127

15. Gray G W and Goodby J W 1984 Smectic Liquid Crytals (Glasgow, UK: Leonard Hill)

16. Shandryuk G A, Kuptsov S A, Shatalova A M, Plate N A and Talroze R V 2003 Macromolecules 363417

17. Xu J, Toh C L, Liu X, Wang S, He C and Lu X 2005 Macromolecules 381684

18. Han X, Zhang S, Shanks R A and Pavel D 2008 React. Funct. Polym. 681097

19. Grimsdale A C and Müllen K 2005 Angew. Chem. Int. Ed. 445592

20. Serpe M J and Craig S L 2007 Langmuir 231626

21. Delphia Shalini Rosalyn P, Senthil S, Kannan P, Vinitha G and Ramalingam A 2007 J. Phys. Chem. Solids 68 1812

22. Kumaresan S and Kannan P 2003 J. Polym. Sci: Part A: Polym. Chem. 413188

23. Kawatsuki N, Unisuga S, Neko T, Uchida E and Kondo M 2009 React. Funct. Polym. 69836

24. Sakthivel P and Kannan P 2005 Polymer 469821

25. Shibaev V P, Kostromin S G and Plate N A 1982 Eur. Polym. J. 18651

26. Zentel R, Schmidt G F, Mayer J and Benalia M 1987a Liq. Cryst. 283

27. Bennett G M and Jones B 1939 J. Chem. Soc. 420

28. Perrin D D and Armarego W L F 1988 Purification of laboratory chemicals (New York: Pergamon Press) pp. $1-378$

29. Itahara T and Yokogawa Y 2007 J. Mol. Struct. 82795

30. Saravanan C, Ambili V and Kannan P 2010 React. Funct. Polym. 70217 